\title{
pneumonia
}

Review

\section{The respiratory microbiota during health and disease: a paediatric perspective}

\author{
Ilan JN Koppen ${ }^{a, b^{*}}$, Astrid ATM Bosch ${ }^{a, b^{*}}$, Elisabeth AM Sanders ${ }^{a}$, Marlies A van Houten ${ }^{b}$, \\ Debby Bogaert ${ }^{\mathrm{a}}$
}

a Department of Paediatric Immunology and Infectious Diseases, Wilhelmina Children Hospital, University Medical Centre Utrecht, the Netherlands; bSpaarne Gasthuis Academy, Hoofddorp and Haarlem, the Netherlands

Corresponding author: Debby Bogaert, Wilhelmina Children's Hospital, Lundlaan 6, 3584 EA Utrecht, the Netherlands. Phone: +318875555 55/51754. Email: D.Bogaert@umcutrecht.nl

Author contributions: All the authors met ICMJE authorship criteria. IK, $A B, E S, M H, D B$ generated and designed the research plan. IK, $A B$ wrote the first draft of the manuscript. All authors contributed to the writing of the manuscript. All authors critically reviewed the manuscript for important intellectual content. All authors approved the final version of the manuscript.

*IK and $\mathrm{AB}$ contributed equally to this work.

Received 29 April 2015; Accepted 23 July 2015; Published 22 September 2015

Citation: Koppen IJN, Bosch AATM, Sanders EAM, van Houten MA, Bogaert D. The respiratory microbiota during health and disease: a paediatric perspective. pneumonia 2015;6:90-100

\begin{abstract}
Recent studies investigating the relationship between the microbiota and disease are demonstrating novel concepts that could significantly alter the way we treat disease and promote health in the future. It is suggested that the microbiota acquired during childhood may shape the microbial community and affect immunological responses for later life, and could therefore be important in the susceptibility towards disease. Several diseases, including asthma, pneumonia, and otitis media, are associated with changes in composition and diversity of the respiratory microbiota. This review summarises current literature, focusing on the composition and development of the respiratory microbiota in children and its relationship with respiratory diseases.
\end{abstract}

Keywords: microbiome, microbiota, respiratory infections, children, paediatric, respiratory tract 


\section{Introduction}

Lower respiratory tract infections remain one of the leading causes of mortality in young children worldwide, accounting for 1.4 to 1.8 million deaths annually [1]. Upper respiratory tract infections contribute considerably to healthcare utilisation in the paediatric population. Otitis media (OM), in particular, is a major cause for healthcare visits and antibiotic prescriptions among children [2]. Respiratory tract infections are frequently caused by respiratory viruses and potentially pathogenic bacteria (including Streptococcus pneumoniae, Haemophilus influenzae, Moraxella catarrhalis, and Staphylococcus aureus), or a combination of both viruses and bacteria; however, asymptomatic carriage with these potential pathogens also commonly occurs $[3,4]$. This contradictory finding suggests that the pathophysiology of respiratory infections is more complex than previously assumed. Moreover, a growing body of evidence suggests that susceptibility to respiratory tract infections is influenced by a number of factors related to the microbial communities that reside in (and on) the human body and involves more than mere colonisation with potential pathogens.

Over the last decade it has become clear that humans live in symbiosis with their abundant resident microbes, with bacterial cells outnumbering human cells by an estimated factor of 10 [5-7]. Advances in culture-independent techniques have enabled us to identify and accurately detect species that could not be detected by culturebased methods in the past [8]. These advances in the field of molecular techniques, in particular metagenomics, have led to the definition of the human microbiota, a term that refers to the complex microbial ecosystem in and on our bodies. The human microbiota is assumed to play an important role in human health by protecting the host against invading pathogens, contributing to the development of both innate and adaptive immunity, and aiding host nutrition and metabolite digestion $[5,9,10]$. Strong associations between microbiota characteristics and disease susceptibility have been described for a wide spectrum of diseases (e.g. inflammatory bowel disease, asthma, psoriasis, and colorectal cancer) $[5,9,11]$.

Investigating the role of the microbiota in health and disease is a relatively new, rapidly developing field of research. Since the human microbiota has been shown to be associated with susceptibility to a wide variety of diseases, it can be hypothesised that the microbiota of the respiratory tract is involved in containment of potential pathogens as well; therefore, changes in microbial composition of the respiratory tract may increase susceptibility to respiratory diseases. A better understanding of respiratory infection pathogenesis is needed to identify novel therapeutic possibilities. This review summarises current knowledge on the composition and diversity of the microbiota of the respiratory tract and its possible relationship with the development of respiratory diseases.

\section{The microbiota of the respiratory tract from a health perspective}

The mucosal surface of the respiratory tract is in contact with the outside world with every breath we take. The microbial communities that reside in the different niches of the respiratory tract differ significantly, which is most probably driven by the interplay between environmental influences (e.g. temperature, humidity, and oxygen saturation), anatomical factors, and epithelial characteristics and functions. Despite the significant differences between different niches along the respiratory tract, there is an overlap in microbial communities found in neighbouring niches, presumably as a consequence of anatomical adjacency and similar environmental conditions [12]. An overview of microbiota composition differences between these niches in the respiratory tract is discusssed.

The frontal part of the nose, the nares (nostrils), is anatomically located in a way that renders it highly susceptible to influences from the outside world. The microbiota of the nares harbours a very diverse bacterial community, including commensals and potential pathogens. In children, Gram-positive aerobes such as Staphylococcus, Streptococcus (mainly Streptococcus salivarius and Streptococcus mitis), Dolosigranulum, Corynebacterium, Gemella, Granulicatella spp., and (to a lesser extent) Gram-negative aerobes commonly found in adults such as Moraxella, Haemophilus, and Neisseria spp. have been described [13]. The nasopharynx, which connects the nose and oropharynx, is a well-known reservoir for potential pathogens that are able to cause respiratory tract infections: its microbiota composition resembles that of the nares, although Gram-negative and anaerobic bacteria are more predominant presumably due to the ecological circumstances [4]. The prevalence of the Staphylococcaceae family, including $S$. aureus, seems to be inversely correlated with prevalence of commensals of the Corynebacteriaceae and Propionibacteriaceae families [14]. This inverse relationship between specific commensals and potential pathogens might indicate that bacterial interactions play an important role in the composition of the microbiota in this niche.

Due to its anatomy and function, the oral cavity is strongly influenced by feeding. It harbours a highly diverse microbiota, characterised by Streptococcus, Actinomyces, Gemella, and Veillonella spp. There are many similarities and overlap between the oral microbiota composition and the microbiota of the nasopharynx and lungs $[5,15]$.

Studying the lung microbiota is a relatively new field and sampling of healthy subjects for research purposes is difficult due to its invasive character. Although the lungs were classically believed to be sterile, recent cultureindependent studies have shown otherwise $[11,16]$. The members of the lung microbiota resemble those of the upper respiratory tract microbiota, although the bacterial density is much lower [12]. It remains unclear, 
however, whether the microbiota as observed in the lower respiratory tract of healthy individuals resembles a true ecosystem, or if it is the result of contamination during sampling, or continuous microaspiration from the upper respiratory tract [17].

\subsection{Development of the respiratory tract microbiota with age}

Until recently, it was believed that the intrauterine environment was sterile. However, culture-independent techniques have challenged this dogma [18]. Birth is considered by many to be the main starting point of the establishment of the human microbiota $[5,19,20]$. During the first weeks of newborn life, the microbiota of different body sites, including the respiratory tract, will start to develop. This process is most likely dependent on internal factors such as genetic predisposition, and external factors-most notably, the maternal microbiota and mode of delivery $[9,11]$ (Figure 1).

Mode of delivery is presumed to be of key importance in the initial development of the microbiota [5]. In vaginally delivered children, the first bacterial communities in the respiratory tract resemble the vaginal microflora from the mother (Lactobacillus, Prevotella, or Sneathia spp.) whereas children born by Caesarean section are predominantly colonised by skin-type bacteria such as Staphylococcus, Corynebacterium, and Propionibacterium spp. $[5,20]$. A comparable pattern of colonisation succession seems to take place in the microbiota of the skin, gut, and airways [20]. Mode of delivery, therefore, seems to determine the initial colonisation of all body sites of the newborn and is a potential driver for the nichespecific differentiation that occurs afterwards.

One of the first major encounters in early life is food; breastfeeding and formula-feeding impose selective effects on the composition of the intestinal microbiota of infants regarding the abundance of certain genera such as Bifidobacterium and Lactobacillus [5,7,19,21]. Part of this effect is ascribed to human milk oligosaccharides that stimulate the growth of Bifidobacterium spp. [5]. It is likely that feeding also shapes the microbiota of other niches, such as the respiratory niches. This is supported by a recent study by Biesbroek et al. [22], which showed

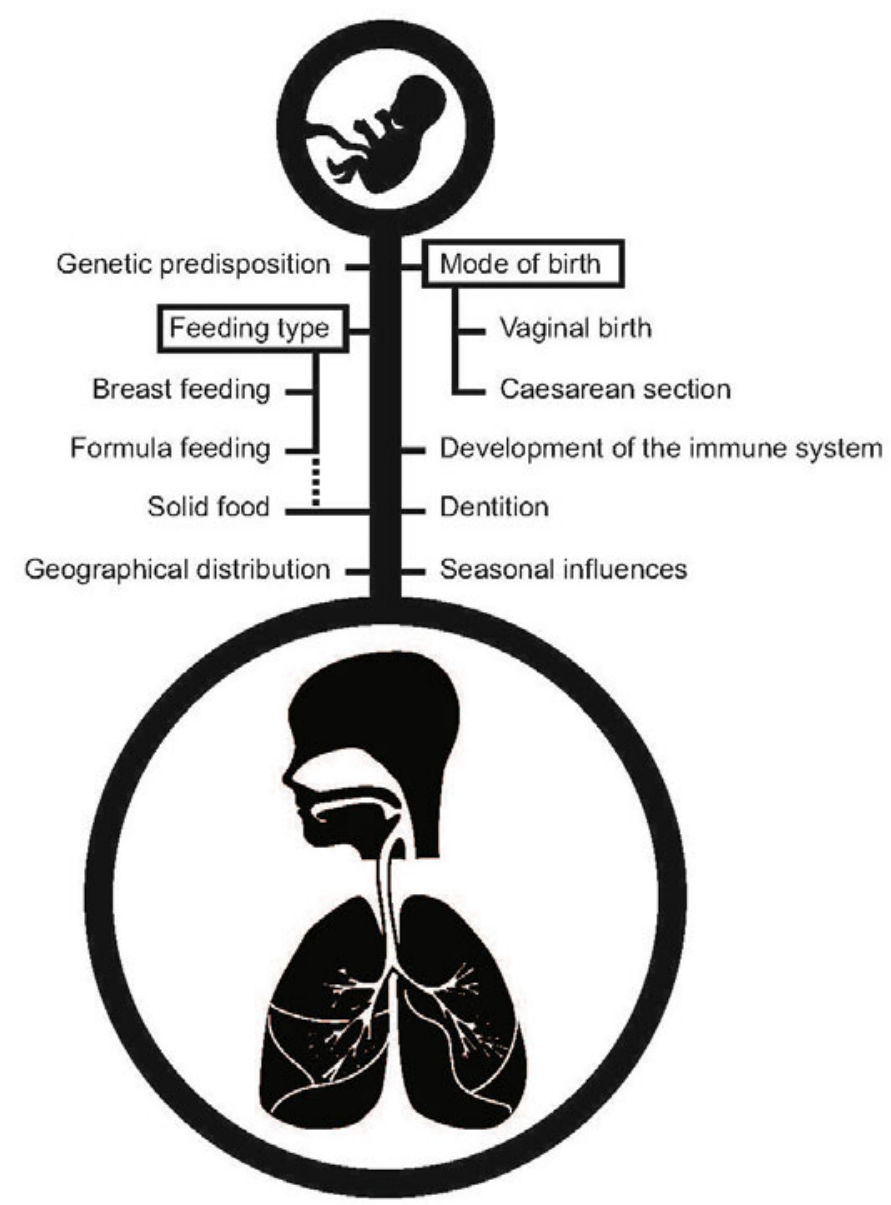

Figure 1 Schematic representation of internal and external drivers of development of the respiratory microbiota in the first years of life 
that the nasopharyngeal microbiota composition differs significantly between breastfed and formula-fed young infants. In this study, breastfed children had significantly higher abundances of the Gram-positive commensals Dolosigranulum and Corynebacterium and decreased abundance of Staphylococcus spp. Even more interesting is that this difference in microbiota composition appeared to correlate with respiratory health: infants with Dolosigranulum- and Corynebacterium-dominated nasopharyngeal microbiota experienced decreased numbers of episodes of respiratory infections with wheezing or symptoms of respiratory infections in the consecutive months of life.

In general, the composition of the early microbiota seems to be determinative in shaping the microbiota later in life. In a recent study by our research group, we showed that respiratory profiles at 6 weeks of age were associated with stability and patterns of change over the first 24 months of life [23]. Moreover, stability of microbiota was inversely associated with symptoms of respiratory infections in the consecutive periods. Therefore, the composition of the early microbiota may play an important role in the stability and composition of the microbiota profile later on during childhood. Furthermore, maturation of the immune system will have an effect on, but inversely will also be influenced by, the microbiota composition over time [4,24-29].

\subsection{Dysbiosis of the microbiota}

The discovery of penicillin by Alexander Fleming in 1928 has been crucial for current medical practice. Nowadays, children in developed countries generally receive between 10 and 20 courses of antibiotics before reaching adulthood [30]. Extensive antibiotic use has, however, led to the development of antibiotic resistance, which is a major reason for increased efforts on antibiotic stewardship worldwide. Additionally, antibiotic treatment is assumed to elicit major perturbations of the human microbiota [31-33]. In the gut, antibiotics cause a disruption of microbiota composition as well as a decrease in biodiversity [34]. The same profound effect of antibiotics has been described for the respiratory microbiota [3540]. The consequences of a lower biodiversity are not yet fully understood although recent data show a strong association between decreased taxonomic richness and evenness of microbial communities and diseases such as necrotising enterocolitis and inflammatory bowel diseases [5]. Antibiotic use during infancy has also been associated with antibiotic consumption and risk of developing asthma and obesity over time $[9,41,42]$. More research is needed to elucidate the effects of antibiotic treatment regimens on the microbiota in both the short and long term.

Vaccines targeting respiratory pathogens are also considered to have an important impact on the respiratory microbiota composition. For example, the introduction of the pneumococcal conjugate vaccines has been shown to elicit a major effect on the composition of the respiratory microbiota. Although a significant decrease in colonisation with vaccine serotypes pneumococci was observed, the vacant niche was rapidly filled by non-vaccine serotypes $[43,44]$. In addition, pneumococcal conjugate vaccines have provoked an effect on the microbiota of the respiratory tract that transcends the elimination of S. pneumoniae. Culture-based studies showed that $S$. aureus and $H$. influenzae were persistently present in the nasopharynx of young children and their parents after the introduction of the vaccine, compared to pre-vaccination $[43,45]$. Through 16S-based sequencing, a higher inter-individual variability in microbiota composition and increased diversity of bacterial species were observed in immunised children at 12 months of age when compared to non-immunised children 1 month following a booster vaccination [46]. As expected, the composition of the nasopharyngeal microbiota of these vaccinated children was characterised by a decrease in pneumococcal presence; however, nonpneumococcal streptococcal, and anaerobic bacterial presence increased and an apparent higher abundance of Haemophilus and Staphylococcus was observed. Although these differences might display a temporary effect, the long-term health effects of these changes are not fully known and need to be further investigated.

\subsection{Interspecies interaction}

In addition to the presence or absence of certain bacteria, it is believed that bacterial interactions play an important role in pathogenesis of respiratory infections. For example, children with high levels of Rothia, Gemella, Actinomyces, Veillonella, and Granulicatella are less likely to be colonised with S. pneumoniae in the upper respiratory tract [35]. In contrast, pneumococcal carriage is negatively associated with the presence of bacteria including $S$. salivarius, $S$. mitis, and $S$. aureus, suggesting negative interactions between these species $[37,47,48]$. Moreover, carriage of species including $S$. pneumoniae, $H$. influenzae, or $M$. catarrhalis is associated with lower microbial diversity in upper respiratory tract flora $[35,49]$. It remains unclear whether microbial diversity is independently associated with respiratory health characteristics or merely relies on microbial community composition.

Besides bacterial interactions, viruses appear to play an important role in respiratory health in children. Viral infections often precede a bacterial superinfection [50]. Similar to asymptomatic carriage of potential pathogenic bacteria, respiratory viruses seem to inhabit the respiratory tract of healthy children frequently, forming the so-called virome $[3,50,51]$. Therefore interactions between viruses and bacteria are potentially of great significance in the phases preceding respiratory tract infections as well.

\section{The microbiota during respiratory tract diseases}

It has been hypothesised that the composition of the microbiota in the respiratory tract might be altered during respiratory diseases. We describe the literature regarding associations between microbial composition and upper and lower respiratory tract infections, cystic fibrosis (CF), 
bronchopulmonary dysplasia (BPD), and asthma.

\subsection{Upper respiratory tract infections}

$\mathrm{OM}$ is one of the most common paediatric infectious diseases, affecting the majority of children in developed and developing countries [2,52]. It is a major reason for healthcare visits and antibiotic prescription in children $[2,49,53]$.

$\mathrm{OM}$ is frequently associated with viral respiratory infections; however, it can also be caused by bacterial pathogens. The most commonly observed bacterial species in OM are $S$. pneumoniae, $H$. influenzae, and $M$. catarrhalis $[39,54]$. Mixed cultures with other species are also found, making it difficult to differentiate between causal and bystander effects.

Microbiota studies of the upper respiratory tract in relation to respiratory infections are scarce. However, Pettigrew and colleagues [35] observed that an increased presence of Streptococcus and Haemophilus was associated with a decreased presence of Corynebacterium and Dolosigranulum in the upper respiratory tract of children with a respiratory infection, suggesting a possible protective effect of the latter species in the development of upper respiratory tract infections. In another study, Hilty et al. [39] compared nasopharyngeal swabs of controls and infants with acute $\mathrm{OM}$, and reported a significantly higher abundance of Staphylococcaceae in controls and a non-significant trend towards a higher abundance of Moraxellaceae, Streptococcaceae, and Pasteurellaceae in children with acute OM.

Nasal colonisation with potential otopathogens such $S$. pneumoniae, $H$. influenzae, and $M$. catarrhalis is also associated with lower levels of microbial biodiversity in the upper respiratory tract $[35,39,49]$. This suggests that a decrease in microbial diversity, together with the emergence of potential pathogens, might precede upper respiratory tract infections.

\subsection{Lower respiratory tract infections}

Pneumonia is one of the leading causes of mortality in children worldwide [55]. Although respiratory syncytial virus and influenza virus are described as the most common viral pathogens $(29 \%$ and $17 \%$ of all episodes of pneumonia, respectively), most pneumonia-related deaths are caused by bacteria such as $S$. pneumoniae (33\%) and $H$. influenzae type b (16\%) [55].

There is a lack of knowledge regarding the role of respiratory microbiota in susceptibility to pneumonia. A recent study investigating the nasopharyngeal microbiota in children with pneumonia showed that viral pneumonia is associated with an increased abundance of $M$. lacunata in the upper respiratory tract, whilst non-viral (and therefore presumably bacterial) pneumonia is associated with a high abundance of $S$. pneumoniae, $H$. influenzae, and $M$. catarrhalis in comparison to healthy controls [56]. In line with previous studies investigating infectious diseases, pneumonia was associated with a lower microbial biodiversity $[5,56]$. Unfortunately, the authors could not identify health-associated bacteria, possibly as a result of a lack of statistical power.

\subsection{Cystic fibrosis}

CF is one of the most common lethal genetic diseases in Caucasians $[57,58]$. In CF, a mutation in the CF transmembrane conductance regulator (CFTR) gene results in altered ion transport affecting multiple body systems, including the respiratory tract. In the airways, CF causes hyperviscosity of secretions, impairing mucociliary clearance and promoting stasis and accumulation of mucus. This facilitates chronic respiratory infections that require frequent and chronic treatment with broad-spectrum antibiotics. Culture-dependent studies have identified a small number of bacteria as common CF pathogens in children, including Pseudomonas aeruginosa, S. aureus, $S$. pneumoniae, H. influenzae, and Burkholderia cepacia [5759]. New culture-independent techniques have improved the knowledge on the complex microbial ecosystems in the airways of paediatric CF patients. A wide range of bacteria is now found to be associated with CF, although their role in the pathogenesis of respiratory diseases is still uncertain [60-62]. The microbial biodiversity of the CF lung has been shown to increase in the first few months of life, then peak during childhood with a predominance of $H$. influenzae and $S$. aureus, followed by a decrease in microbial diversity during the second decade of life when it is generally predominated by a few antibiotic-resistant pathogens including $P$. aeruginosa [58-60,63,64]. The decrease in microbial diversity and the presence of $P$. aeruginosa have been strongly associated with severity of disease [58,61,63-65]. Moreover, $P$. aeruginosa inversely correlates with lung function and microbial diversity $[62-64,66,67]$. It is believed that frequent antibiotic treatment plays an important role in the decrease in microbial biodiversity over time. Additionally, a correlation between diversity of the microbiota and CFTR genotype has been reported $[63,64]$. In summary, the CF lung microbiota is generally characterised by a decreased microbial biodiversity and an increased abundance of CF pathogens over time, which is likely to be influenced by multiple factors including repeated and chronic antibiotic treatment as well as chronic inflammation. The relationship between microbiota composition, inflammation and lung function deterioration deserves more in depth study-this information may help to predict the course of disease, and might help to treat acute and chronic infections with alternative methods.

\subsection{Bronchopulmonary dysplasia}

Bronchopulmonary dysplasia (BPD) is a lung disease characterised by inflammation and scarring that occurs in premature children. In infants born before 28 weeks of gestational age, $50-80 \%$ develop BPD; therefore, BPD 
accounts for the vast majority of cases of chronic lung disease in young infants [68]. The pathogenesis of BPD is complex and seems to be multifactorial. Several studies using new molecular techniques suggested that the (initial) composition of the microbial community may be associated with the development of BPD, for example, by affecting inflammation and/or chronic microbial infections [69-75]. A recent study in preterm infants (24-32 weeks of gestational age) showed that endotracheal aspirates of infants who developed BPD showed a less diverse respiratory microbiota in comparison to infants who did not develop BPD [76]. This study also showed that the microbiota composition of infants who would develop BPD was less stable over time and that it was characterised by an increased abundance of Klebsiella and Staphylococcus spp. Moreover bacterial presence in respiratory samples, regardless of the bacterial species, has been associated with BPD $[69,70,73]$. This may indicate a possible infectious aetiology.

Special interest has been paid to the presence of Ureaplasma spp. in the respiratory tract and the development of BPD/chronic lung disease $[69,71,72,74]$. The presence of Ureaplasma spp. appears to be associated with increased severity of the disease but also with other known risk factors for the development of BPD such as lower gestational age, lower birth weight and the ocurrence of chorioamnionitis, which makes it hard to unravel the direct cause and effect relationships $[71,72,75,76]$.

\subsection{Asthma}

Asthma is a chronic inflammatory respiratory disorder mediated by a multitude of immune cell types and inflammatory mediators produced by mast cells, eosinophils, Th2 lymphocytes and interleukines [77]. Its exact aetiology and pathogenesis are still poorly understood. Recently, it has been postulated that respiratory bacteria might actually play a causative role in the pathogenesis of asthma itself, rendering it to be a chronic infectious disease rather than sterile inflammation $[78,79]$.

A diverse microbial environment seems to enhance a more diverse human microbiota, thereby protecting against development of atopic diseases $[80,81]$. In line with this, several studies have demonstrated that early life antibiotic treatment (which causes a decrease in microbial biodiversity) is associated with asthma $[82,83]$. This is supported by research showing that asthmatic patients with higher microbial diversity may have a better lung function $[84,85]$.

Similar to what is observed in adults [84-86], the respiratory microbiota of asthmatic or wheezing children is characterised by a high abundance of Proteobacteria, especially $H$. influenzae [86]. In other studies, members of Staphylococcus, Enterobacteriaceae, Bacteroides, and Clostridium spp. have also been associated with asthma $[79,87]$. Also, early life colonisation with $H$. influenzae,
M. catarrhalis, and S. pneumoniae in healthy Danish children has been associated with persistent wheeze over time, which can even develop towards asthma after the first 5 years of life [88]. In line with this, a Streptococcusdominated microbial profile appeared to be a strong asthma predictor, as recently shown in an Australian healthy birth cohort study [89]. Mode of birth delivery has been shown to affect the risk of developing asthma $[90,91]$; children born by Caesarean section were found to be more prone to develop asthma later in life than children born vaginally, which might be linked to early microbiota development that is significantly altered in infants born by caesarean section [20]. Also, antibiotic treatment with macrolides seems to be effective in the treatment of acute asthma exacerbations, especially steroid-resistant asthmatic children [88]. This might imply that bacterial colonisation is of key importance in the pathogenesis of asthma or that macrolide treatment renders an important immunomodulatory effect.

Of the large variety of risk factors that are associated with asthma, many are linked to the gastrointestinal microbiota [92]. An elaborate disquisition on how the gut microbiota may influence the respiratory tract microbiota goes beyond the scope of this review. However, a detailed summary of the literature available on this subject has been described by Bendiks et al. [93].

\section{Discussion}

This review provides a summary of the current literature on the relationship between the respiratory tract microbiota in children and respiratory diseases. The microbiota of the respiratory tract in children with (severe) respiratory diseases seems to differ from that of healthy children. During respiratory infections, colonisation with potential pathogens appears to be enhanced, suggesting a crucial step for infections to emerge. Moreover, loss of microbial biodiversity and a decrease in beneficial commensals are reported during respiratory infections. This might indicate that respiratory infectious diseases are related to microbial dysbiosis. However, due to a lack of longitudinal data, it remains unclear whether these changes in the microbiota are part of causative mechanisms, merely a consequence of respiratory diseases, or part of bystander phenomenon. Prospective cohort studies in combination with in vitro studies on mechanisms of effect are therefore of great importance in revealing the potential role of the microbiota in the pathogenesis of disease. Further welldesigned longitudinal investigations are needed in order to gain more insights into the mechanisms behind microbiota variations and their effect on health. Currently, several initiatives for such studies have been put into effect by our group and others [94].

In addition, this review describes environmental factors that affect the composition and development of the respiratory microbiota. Mode of birth delivery, feeding type, use of antibiotics, and vaccinations might all together have an influence on respiratory microbiota development 
in early life. Longitudinal studies are required to gain more insights into these and other environmental factors that might influence the development of the respiratory microbiota and thereby susceptibility to respiratory diseases.

Microbiota studies are a relatively new field of research and therefore the number of studies regarding the respiratory microbiota in children and infectious respiratory diseases is still relatively small. Moreover, many studies use small participant groups, which makes it difficult to draw solid conclusions. One impediment in comparing data is the variation in age groups among different studies, since age itself has been shown to be an important determinant in the development of the microbiota. Also, geographical and seasonal influences might differ between studies. In addition, it can be difficult to compare studies because methodology (e.g. sample technique, study design, and tools used for analyses) and study populations vary between studies. Nevertheless, it is a very promising research field and new, larger (preferably longitudinal) studies are needed in order to clarify the exact role of the microbiota and other environmental determinants in paediatric health and disease. This is of major importance, as antibiotic resistance is on the rise and alternative treatment options are needed. Novel molecular research methods might enable us to design innovative ways of prevention and treatment of diseases, because by altering the microbiota of individuals it might be possible to intervene in pathways leading to disease. Illustrating this, there has been an increasing interest in the use of preand probiotics during the past decades. It is hypothesised that by promoting beneficial bacteria, diseases might be prevented or treated [95-97]. A meta-analysis of the effect of probiotics on treatment or prevention of respiratory infections showed a positive though modest effect [98]. The complexity and heterogeneity in microbial ecosystems between individuals means that a 'one cure fits all' strategy seems to be oversimplified.

\section{Conclusion}

In conclusion, this review shows that the respiratory microbiota of healthy children differs from that of children suffering from respiratory diseases. The latter group is mainly characterised by colonisation profiles containing high abundance of potential pathogens, a loss of microbial biodiversity, and a decrease of (beneficial) commensals. Prospective studies taking into account the temporal variability of the microbiota and comparing patients with healthy subjects, will provide a better understanding of the role of the microbiota in the dynamics of the pathogenesis of respiratory disease. This could provide the basis for new ways to prevent and treat respiratory diseases in children in the future.

\section{Search strategy and selection criteria}

We identified references for this review by searches in different databases (PubMed, Embase, PiCarta and the Cochrane library), and references from relevant articles. The following MeSH headings were used: "Infant, Newborn", "Infant", "Child, Preschool", "Child", "Adolescent", "Respiratory System", "Respiratory Tract Diseases", "Microbiome", "Metagenome", "Metagenomic", "16s ribosomal rna". In addition the following text words were used: "newborn*", "infan*", "child*", "adolescen*", "pediatric*", "paediatric*”, "neonat*", "airway*", "lung*”, "nasopharyn*", "respiratory", "pulmonary", "sinus*", "otiti*", "pharyngitis", "bronchitis", "bronchiolitis", "pneumonia", "bronchopulmonary dysplasia", "chronic lung disease", "asthma*", "astma*", "cystic fibrosis", "microbiome*", "metagenome*", "microbiota*", "pyrosequencing", "culture independent", "cultureindependent", "16 s", "16s", "microbial communit*", "bacterial communit*", "bacterial carriage", "viral carriage", "viral communities", "microflora".

This search resulted in 896 references, which were all further assessed by reading the title and abstract. Only articles published in English were included. We further assessed the references of all selected publications. The final reference list was generated on the basis of relevance to the topics covered in this review.

\section{Acknowledgements}

The authors would like to thank Floris Heyne, Amsterdam, the Netherlands, for providing technical support with Figure 1.

Funding: The authors have no funding to report.

Competing interests: ES declares to have received unrestricted research support from Pfizer, grant support for vaccine studies from Pfizer and GalaxoSmithKline (GSK) and fees paid to the Institution for advisory boards or participation in independent data monitoring committees for Pfizer and GSK. All other authors declare no competing interests.

Provenance and peer review: Not commissioned; externally peer reviewed.

Copyright: This is an open-access article distributed under the terms of the Creative Commons Attribution License, which permits unrestricted use, distribution, and reproduction in any medium, provided the original author and source are credited.

\section{References}

1. Liu L, Johnson HL, Cousens S, Perin J, Scott S, Lawn JE et al.; Child Health Epidemiology Reference Group of WHO and UNICEF. Global, regional, and national causes of child mortality: an updated systematic analysis for 2010 with time trends since 2000. Lancet 2012;379:2151-61. PMID:22579125 http://dx.doi.org/10.1016/S01406736(12)60560-1

2. Monasta L, Ronfani L, Marchetti F, Montico M, Vecchi Brumatti L, Bavcar A et al. Burden of disease caused by otitis media: systematic review and global estimates. PLoS ONE 2012;7:e36226. PMID:22558393 http://dx.doi. org/10.1371/journal.pone.0036226

3. van den Bergh MR, Biesbroek G, Rossen JW, de Steenhuijsen Piters WA, Bosch AA, van Gils EJ et al. Associations 
between pathogens in the upper respiratory tract of young children: interplay between viruses and bacteria. PLoS ONE 2012;7:e47711. PMID:23082199 http://dx.doi. org/10.1371/journal.pone.0047711

4. Bogaert D, Keijser B, Huse S, Rossen J, Veenhoven R, van Gils $E$ et al. Variability and diversity of nasopharyngeal microbiota in children: a metagenomic analysis. PLoS ONE 2011;6:e17035. PMID:21386965 http://dx.doi. org/10.1371/journal.pone.0017035

5. Johnson $\mathrm{CL}$, Versalovic J. The human microbiome and its potential importance to pediatrics. Pediatrics 2012;129:950-60. PMID:22473366 http://dx.doi. org/10.1542/peds.2011-2736

6. Turnbaugh PJ, Ley RE, Hamady $M$, Fraser-Liggett $C M$, Knight R, Gordon Jl. The human microbiome project. Nature 2007;449:804-10. PMID:17943116 http://dx.doi. org/10.1038/nature06244

7. Wopereis $\mathrm{H}$, Oozeer R, Knipping K, Belzer C, Knol J. The first thousand days - intestinal microbiology of early life: establishing a symbiosis. Pediatr Allergy Immunol 2014;25:428-38. PMID:24899389 http://dx.doi. org/10.1111/pai.12232

8. Hayashi $\mathrm{H}$, Sakamoto M, Benno Y. Phylogenetic analysis of the human gut microbiota using 16S rDNA clone libraries and strictly anaerobic culture-based methods. Microbiol Immunol 2002;46:535-48. PMID:12363017 http://dx.doi. org/10.1111/j.1348-0421.2002.tb02731.x

9. Cho I, Blaser MJ. The human microbiome: at the interface of health and disease. Nat Rev Genet 2012;13:260-70. PMID:22411464

10. Human Microbiome Project Consortium. Structure, function and diversity of the healthy human microbiome. Nature 2012;486:207-14. PMID:22699609 http://dx.doi. org/10.1038/nature11234

11. Beck JM, Young VB, Huffnagle GB. The microbiome of the lung. Transl Res 2012;160:258-66. PMID:22683412 http:// dx.doi.org/10.1016/j.trsl.2012.02.005

12. Charlson ES, Bittinger $K$, Haas AR, Fitzgerald AS, Frank I, Yadav A et al. Topographical continuity of bacterial populations in the healthy human respiratory tract. Am J Respir Crit Care Med 2011;184:957-63. PMID:21680950 http://dx.doi.org/10.1164/rccm.201104-06550C

13. Oh J, Conlan S, Polley EC, Segre JA, Kong HH. Shifts in human skin and nares microbiota of healthy children and adults. Genome Med 2012;4:77. PMID:23050952 http://dx.doi. org/10.1186/gm378

14. Lemon KP, Klepac-Ceraj V, Schiffer HK, Brodie EL, Lynch SV, Kolter R. Comparative analyses of the bacterial microbiota of the human nostril and oropharynx. MBio 2010;1:e0012910. PMID:20802827

15. Lif Holgerson P, Harnevik L, Hernell O, Tanner AC, Johansson I. Mode of birth delivery affects oral microbiota in infants. J Dent Res 2011;90:1183-8. PMID:21828355 http://dx.doi. org/10.1177/0022034511418973

16. Beck JM. ABCs of the lung microbiome. Ann Am Thorac Soc 2014;11 Suppl 1:S3-6. PMID:24437402 http://dx.doi. org/10.1513/AnnalsATS.201306-188MG

17. Bogdanos DP, Smyk D, Shoenfeld Y. The microbiome of the lung. Isr Med Assoc J 2013;15:766-7. PMID:24449982

18. Prince AL, Antony KM, Chu DM, Aagaard KM. The microbiome, parturition, and timing of birth: more questions than answers. J Reprod Immunol 2014;104105:12-9. PMID:24793619 http://dx.doi.org/10.1016/j. jri.2014.03.006

19. Ogra PL, Welliver RC Sr. Effects of early environment on mucosal immunologic homeostasis, subsequent immune responses and disease outcome. Nestle Nutr Workshop Ser Pediatr Program 2008;61:145-81. PMID:18196951

20. Dominguez-Bello MG, Costello EK, Contreras M, Magris $M$, Hidalgo $G$, Fierer $N$ et al. Delivery mode shapes the acquisition and structure of the initial microbiota across multiple body habitats in newborns. Proc Natl Acad Sci USA 2010;107:11971-5. PMID:20566857 http://dx.doi. org/10.1073/pnas.1002601107

21. Penders J, Thijs C, Vink C, Stelma FF, Snijders B, Kummeling I et al. Factors influencing the composition of the intestinal microbiota in early infancy. Pediatrics 2006;118:511-21. PMID:16882802 http://dx.doi.org/10.1542/peds.20052824

22. Biesbroek G, Bosch AA, Wang X, Keijser BJ, Veenhoven $\mathrm{RH}$, Sanders EA et al. The impact of breastfeeding on nasopharyngeal microbial communities in infants. Am J Respir Crit Care Med 2014;190:298-308. PMID:24921688

23. Biesbroek G, Tsivtsivadze E, Sanders EA, Montijn R, Veenhoven RH, Keijser BJ et al. Early respiratory microbiota composition determines bacterial succession patterns and respiratory health in children. Am J Respir Crit Care Med 2014;190:1283-92. PMID:25329446 http://dx.doi. org/10.1164/rccm.201407-12400C

24. Caporaso JG, Lauber CL, Costello EK, Berg-Lyons D, Gonzalez A, Stombaugh J et al. Moving pictures of the human microbiome. Genome Biol 2011;12:R50. PMID:21624126 http://dx.doi.org/10.1186/gb-2011-12-5-r50

25. Turnbaugh PJ, Hamady M, Yatsunenko T, Cantarel BL, Duncan A, Ley RE et al. A core gut microbiome in obese and lean twins. Nature 2009;457:480-4. PMID:19043404 http://dx.doi.org/10.1038/nature07540

26. Topcuoglu N, Keskin F, Ciftci S, Paltura C, Kulekci M, Ustek $D$ et al. Relationship between oral anaerobic bacteria and otitis media with effusion. Int J Med Sci 2012;9:256-61. PMID:22606045 http://dx.doi.org/10.7150/ijms.4382

27. Costello EK, Lauber CL, Hamady M, Fierer N, Gordon JI, Knight R. Bacterial community variation in human body habitats across space and time. Science 2009;326:16947. PMID:19892944 http://dx.doi.org/10.1126/ science. 1177486

28. Nayak DM, Kumar N, Bhaskaranand N, Nayak C. Bacterial profile of the oropharynx in infants: an assessment of the confounding factors for colonization. Indian J Pediatr 2011;78:807-11. PMID:21340728 http://dx.doi. org/10.1007/s12098-011-0367-3

29. Verhaegh SJ, Streefland A, Dewnarain JK, Farrell DJ, van Belkum A, Hays JP. Age-related genotypic and phenotypic differences in Moraxella catarrhalis isolates from children and adults presenting with respiratory disease in 20012002. Microbiology 2008;154:1178-84. PMID:18375810 http://dx.doi.org/10.1099/mic.0.2007/015057-0

30. Sharland M; SACAR Paediatric Subgroup. The use of antibacterials in children: a report of the Specialist Advisory Committee on Antimicrobial Resistance (SACAR) Paediatric 
Subgroup. J Antimicrob Chemother 2007;60 Suppl 1:i15-26. PMID:17656377 http://dx.doi.org/10.1093/jac/dkm153

31. Blaser M. Antibiotic overuse: Stop the killing of beneficial bacteria. Nature 2011;476:393-4. PMID:21866137 http:// dx.doi.org/10.1038/476393a

32. Blaser MJ, Falkow S. What are the consequences of the disappearing human microbiota? Nat Rev Microbiol 2009;7:887-94. PMID:19898491 http://dx.doi. org/10.1038/nrmicro2245

33. Costello EK, Stagaman K, Dethlefsen L, Bohannan BJ, Relman DA. The application of ecological theory toward an understanding of the human microbiome. Science 2012;336:1255-62. PMID:22674335 http://dx.doi. org/10.1126/science. 1224203

34. Dethlefsen $\mathrm{L}$, Huse $\mathrm{S}$, Sogin $\mathrm{ML}$, Relman DA. The pervasive effects of an antibiotic on the human gut microbiota, as revealed by deep $16 \mathrm{~S}$ rRNA sequencing. PLoS Biol 2008;6:e280. PMID:19018661 http://dx.doi.org/10.1371/ journal.pbio.0060280

35. Pettigrew MM, Laufer AS, Gent JF, Kong Y, Fennie KP, Metlay JP. Upper respiratory tract microbial communities, acute otitis media pathogens, and antibiotic use in healthy and sick children. Appl Environ Microbiol 2012;78:6262-70. PMID:22752171 http://dx.doi.org/10.1128/AEM.01051-12

36. Jakobsson $\mathrm{HE}$, Jernberg $C$, Andersson AF, Sjölund-Karlsson $M$, Jansson JK, Engstrand L. Short-term antibiotic treatment has differing long-term impacts on the human throat and gut microbiome. PLoS ONE 2010;5:e9836. PMID:20352091 http://dx.doi.org/10.1371/journal.pone.0009836

37. Pelton SI. Regulation of bacterial trafficking in the nasopharynx. Paediatr Respir Rev 2012;13:1503. PMID:22726870 http://dx.doi.org/10.1016/j. prrv.2012.04.001

38. Lazarevic V, Manzano S, Gaïa N, Girard M, Whiteson $\mathrm{K}$, Hibbs $\mathrm{J}$ et al. Effects of amoxicillin treatment on the salivary microbiota in children with acute otitis media. Clin Microbiol Infect 2013;19:E335-42. PMID:23565884 http:// dx.doi.org/10.1111/1469-0691.12213

39. Hilty M, Qi W, Brugger SD, Frei L, Agyeman P, Frey PM et al. Nasopharyngeal microbiota in infants with acute otitis media. J Infect Dis 2012;205:1048-55. PMID:22351941 http://dx.doi.org/10.1093/infdis/jis024

40. Flanagan JL, Brodie EL, Weng L, Lynch SV, Garcia O, Brown R et al. Loss of bacterial diversity during antibiotic treatment of intubated patients colonized with Pseudomonas aeruginosa. J Clin Microbiol 2007;45:1954-62. PMID:17409203 http://dx.doi.org/10.1128/JCM.02187-06

41. Hoskin-Parr L, Teyhan A, Blocker A, Henderson AJ. Antibiotic exposure in the first two years of life and development of asthma and other allergic diseases by 7.5 yr: a dose-dependent relationship. Pediatr Allergy Immunol 2013;24:762-71. PMID:24299467 http://dx.doi. org/10.1111/pai.12153

42. Bailey LC, Forrest CB, Zhang P, Richards TM, Livshits A, DeRusso PA. Association of antibiotics in infancy with early childhood obesity. JAMA Pediatr 2014;168:10639. PMID:25265089 http://dx.doi.org/10.1001/ jamapediatrics.2014.1539

43. Spijkerman J, Prevaes SM, van Gils EJ, Veenhoven RH, Bruin $J P$, Bogaert $D$ et al. Long-term effects of pneumococcal conjugate vaccine on nasopharyngeal carriage of $\mathrm{S}$. pneumoniae, S. aureus, $\mathrm{H}$. influenzae and $\mathrm{M}$. catarrhalis. PLoS ONE 2012;7:e39730. PMID:22761879 http://dx.doi. org/10.1371/journal.pone.0039730

44. Golubchik T, Brueggemann AB, Street $T$, Gertz RE Jr, Spencer CC, Ho $T$ et al. Pneumococcal genome sequencing tracks a vaccine escape variant formed through a multifragment recombination event. Nat Genet 2012;44:352-5. PMID:22286217 http://dx.doi.org/10.1038/ng.1072

45. van Gils EJ, Hak E, Veenhoven RH, Rodenburg GD, Bogaert $D$, Bruin JP et al. Effect of seven-valent pneumococcal conjugate vaccine on Staphylococcus aureus colonisation in a randomised controlled trial. PLoS ONE 2011;6:e20229. PMID:21695210 http://dx.doi.org/10.1371/journal. pone.0020229

46. Biesbroek G, Wang X, Keijser BJ, Eijkemans RM, Trzciński $\mathrm{K}$, Rots NY et al. Seven-valent pneumococcal conjugate vaccine and nasopharyngeal microbiota in healthy children. Emerg Infect Dis 2014;20:201-10. PMID:24447437 http:// dx.doi.org/10.3201/eid2002.131220

47. Könönen $E$, Jousimies-Somer $H$, Bryk A, Kilp T, Kilian M. Establishment of streptococci in the upper respiratory tract: longitudinal changes in the mouth and nasopharynx up to 2 years of age. J Med Microbiol 2002;51:723-30. PMID:12358062 http://dx.doi.org/10.1099/0022-1317-519-723

48. Santagati $M$, Scillato $M$, Patanè $F$, Aiello $C$, Stefani $S$. Bacteriocin-producing oral streptococci and inhibition of respiratory pathogens. FEMS Immunol Med Microbiol 2012;65:23-31. PMID:22243526 http://dx.doi. org/10.1111/j.1574-695X.2012.00928.x

49. Laufer AS, Metlay JP, Gent JF, Fennie KP, Kong Y, Pettigrew MM. Microbial communities of the upper respiratory tract and otitis media in children. MBio 2011;2:e00245-10. PMID:21285435 http://dx.doi.org/10.1128/mBio.00245-10

50. Bosch AA, Biesbroek G, Trzcinski K, Sanders EA, Bogaert $D$. Viral and bacterial interactions in the upper respiratory tract. PLoS Pathog 2013;9:e1003057. PMID:23326226 http://dx.doi.org/10.1371/journal.ppat.1003057

51. Lysholm F, Wetterbom A, Lindau C, Darban H, Bjerkner A, Fahlander $\mathrm{K}$ et al. Characterization of the viral microbiome in patients with severe lower respiratory tract infections, using metagenomic sequencing. PLoS ONE 2012;7:e30875. PMID:22355331 http://dx.doi.org/10.1371/journal. pone. 0030875

52. Hoffman HJ, Daly KA, Bainbridge KE, Casselbrant ML, Homøe P, Kvestad E et al. Panel 1: Epidemiology, natural history, and risk factors. Otolaryngol Head Neck Surg 2013;148 Suppl:E1-25. PMID:23536527 http://dx.doi. org/10.1177/0194599812460984

53. John M, Dunne EM, Licciardi PV, Satzke C, Wijburg O, Robins-Browne RM et al. Otitis media among highrisk populations: can probiotics inhibit Streptococcus pneumoniae colonisation and the risk of disease? Eur J Clin Microbiol Infect Dis 2013;32:1101-10. PMID:23512465 http://dx.doi.org/10.1007/s10096-013-1858-0

54. Liu CM, Cosetti MK, Aziz M, Buchhagen JL, ContenteCuomo TL, Price LB et al. The otologic microbiome: a study of the bacterial microbiota in a pediatric patient with chronic serous otitis media using 16SrRNA gene- 
based pyrosequencing. Arch Otolaryngol Head Neck Surg 2011;137:664-8. PMID:21768410 http://dx.doi. org/10.1001/archoto.2011.116

55. Rudan I, O'Brien KL, Nair H, Liu L, Theodoratou E, Qazi S et al.; Child Health Epidemiology Reference Group (CHERG). Epidemiology and etiology of childhood pneumonia in 2010: estimates of incidence, severe morbidity, mortality, underlying risk factors and causative pathogens for 192 countries. J Glob Health 2013;3:010401. PMID:23826505

56. Sakwinska O, Bastic Schmid V, Berger B, Bruttin A, Keitel $\mathrm{K}$, Lepage $\mathrm{M}$ et al. Nasopharyngeal microbiota in healthy children and pneumonia patients. J Clin Microbiol 2014;52:1590-4. PMID:24599973 http://dx.doi. org/10.1128/JCM.03280-13

57. Harris JK, De Groote MA, Sagel SD, Zemanick ET, Kapsner $\mathrm{R}$, Penvari $\mathrm{C}$ et al. Molecular identification of bacteria in bronchoalveolar lavage fluid from children with cystic fibrosis. Proc Natl Acad Sci USA 2007;104:2052933. PMID:18077362 http://dx.doi.org/10.1073/ pnas. 0709804104

58. Hogardt M, Trebesius K, Geiger AM, Hornef M, Rosenecker $J$, Heesemann J. Specific and rapid detection by fluorescent in situ hybridization of bacteria in clinical samples obtained from cystic fibrosis patients. J Clin Microbiol 2000;38:81825. PMID:10655391

59. Bittar F, Richet H, Dubus JC, Reynaud-Gaubert M, Stremler $\mathrm{N}$, Sarles J et al. Molecular detection of multiple emerging pathogens in sputa from cystic fibrosis patients. PLoS ONE 2008;3:e2908. PMID:18682840 http://dx.doi.org/10.1371/ journal.pone. 0002908

60. Madan JC, Koestler DC, Stanton BA, Davidson L, Moulton LA, Housman ML et al. Serial analysis of the gut and respiratory microbiome in cystic fibrosis in infancy: interaction between intestinal and respiratory tracts and impact of nutritional exposures. MBio 2012;3:e00251-12. PMID:22911969 http://dx.doi.org/10.1128/mBio.00251-12

61. Rogers GB, Hart CA, Mason JR, Hughes M, Walshaw MJ, Bruce KD. Bacterial diversity in cases of lung infection in cystic fibrosis patients: $16 \mathrm{~S}$ ribosomal DNA (rDNA) length heterogeneity PCR and 16S rDNA terminal restriction fragment length polymorphism profiling. J Clin Microbiol 2003;41:3548-58. PMID:12904354 http://dx.doi. org/10.1128/JCM.41.8.3548-3558.2003

62. van der Gast CJ, Walker AW, Stressmann FA, Rogers GB, Scott $P$, Daniels TW et al. Partitioning core and satellite taxa from within cystic fibrosis lung bacterial communities. ISME J 2011;5:780-91. PMID:21151003 http://dx.doi. org/10.1038/ismej.2010.175

63. Cox MJ, Allgaier M, Taylor B, Baek MS, Huang YJ, Daly RA et al. Airway microbiota and pathogen abundance in agestratified cystic fibrosis patients. PLoS ONE 2010;5:e11044. PMID:20585638 http://dx.doi.org/10.1371/journal. pone. 0011044

64. Klepac-Ceraj V, Lemon KP, Martin TR, Allgaier M, Kembel SW, Knapp AA et al. Relationship between cystic fibrosis respiratory tract bacterial communities and age, genotype, antibiotics and Pseudomonas aeruginosa. Environ Microbiol 2010;12:1293-303. PMID:20192960 http:// dx.doi.org/10.1111/j.1462-2920.2010.02173.x

65. Rogers GB, Carroll MP, Serisier DJ, Hockey PM, Jones G,
Bruce KD. characterization of bacterial community diversity in cystic fibrosis lung infections by use of 16 s ribosomal DNA terminal restriction fragment length polymorphism profiling. J Clin Microbiol 2004;42:5176-83. PMID:15528712 http://dx.doi.org/10.1128/JCM.42.11.5176-5183.2004

66. Zemanick ET, Harris JK, Wagner BD, Robertson CE, Sagel $\mathrm{SD}$, Stevens MJ et al. Inflammation and airway microbiota during cystic fibrosis pulmonary exacerbations. PLOS ONE 2013;8:e62917. PMID:23646159 http://dx.doi. org/10.1371/journal.pone.0062917

67. Zemanick ET, Sagel SD, Harris JK. The airway microbiome in cystic fibrosis and implications for treatment. Curr Opin Pediatr 2011;23:319-24. PMID:21494150 http://dx.doi. org/10.1097/MOP.0b013e32834604f2

68. Ali Z, Schmidt P, Dodd J, Jeppesen DL. Bronchopulmonary dysplasia: a review. Arch Gynecol Obstet 2013;288:325-33. PMID:23420126 http://dx.doi.org/10.1007/s00404-0132753-8

69. Beeton ML, Maxwell NC, Davies PL, Nuttall D, McGreal E, Chakraborty $\mathrm{M}$ et al. Role of pulmonary infection in the development of chronic lung disease of prematurity. Eur Respir J 2011;37:1424-30. PMID:20884745 http://dx.doi. org/10.1183/09031936.00037810

70. Davies PL, Spiller OB, Beeton ML, Maxwell NC, RemoldO'Donnell E, Kotecha S. Relationship of proteinases and proteinase inhibitors with microbial presence in chronic lung disease of prematurity. Thorax 2010;65:24651. PMID:20335295 http://dx.doi.org/10.1136/ thx.2009.116061

71. Inatomi $\mathrm{T}$, Oue S, Ogihara T, Hira S, Hasegawa M, Yamaoka S et al. Antenatal exposure to Ureaplasma species exacerbates bronchopulmonary dysplasia synergistically with subsequent prolonged mechanical ventilation in preterm infants. Pediatr Res 2012;71:267-73. PMID:22258085 http://dx.doi.org/10.1038/pr.2011.47

72. Oue S, Hiroi M, Ogawa S, Hira S, Hasegawa M, Yamaoka $S$ et al. Association of gastric fluid microbes at birth with severe bronchopulmonary dysplasia. Arch Dis Child Fetal Neonatal Ed 2009;94:F17-22. PMID:18676413 http:// dx.doi.org/10.1136/adc.2008.138321

73. Stressmann FA, Connett GJ, Goss K, Kollamparambil TG, Patel N, Payne MS et al. The use of culture-independent tools to characterize bacteria in endo-tracheal aspirates from pre-term infants at risk of bronchopulmonary dysplasia. J Perinat Med 2010;38:333-7. PMID:20121490 http://dx.doi.org/10.1515/jpm.2010.026

74. Mourani PM, Harris JK, Sontag MK, Robertson CE, Abman $\mathrm{SH}$. Molecular identification of bacteria in tracheal aspirate fluid from mechanically ventilated preterm infants. PLoS ONE 2011;6:e25959. PMID:22016793 http://dx.doi. org/10.1371/journal.pone.0025959

75. Payne MS, Goss KC, Connett GJ, Kollamparambil T, Legg JP, Thwaites $R$ et al. Molecular microbiological characterization of preterm neonates at risk of bronchopulmonary dysplasia. Pediatr Res 2010;67:412-8. PMID:20035248 http://dx.doi. org/10.1203/PDR.0b013e3181d026c3

76. Lohmann P, Luna RA, Hollister EB, Devaraj S, Mistretta TA, Welty SE et al. The airway microbiome of intubated premature infants: characteristics and changes that predict the development of bronchopulmonary dysplasia. Pediatr 
Res 2014;76:294-301. PMID:24941215 http://dx.doi. org/10.1038/pr.2014.85

77. Salvi SS, Babu KS, Holgate ST. Is asthma really due to a polarized $\mathrm{T}$ cell response toward a helper T cell type 2 phenotype? Am J Respir Crit Care Med 2001;164:13436. PMID:11704578 http://dx.doi.org/10.1164/ ajrccm.164.8.2103080

78. Caramori G, Papadopoulos N, Contoli M, Marku B, Forini G, Pauletti A et al. Asthma: a chronic infectious disease? Clin Chest Med 2012;33:473-84. PMID:22929096 http://dx.doi. org/10.1016/j.ccm.2012.06.009

79. Brar T, Nagaraj S, Mohapatra S. Microbes and asthma: the missing cellular and molecular links. Curr Opin Pulm Med 2012;18:14-22. PMID:22113000 http://dx.doi. org/10.1097/MCP.0b013e32834dccc0

80. Ege MJ, Mayer M, Normand AC, Genuneit J, Cookson WO, Braun-Fahrländer $C$ et al.; GABRIELA Transregio 22 Study Group. Exposure to environmental microorganisms and childhood asthma. N Engl J Med 2011;364:7019. PMID:21345099 http://dx.doi.org/10.1056/ NEJMoa1007302

81. Ege MJ, Mayer M, Schwaiger K, Mattes J, Pershagen G, van Hage $M$ et al. Environmental bacteria and childhood asthma. Allergy 2012;67:1565-71. PMID:22994424

82. Kozyrskyj AL, Ernst P, Becker AB. Increased risk of childhood asthma from antibiotic use in early life. Chest 2007;131:1753-9. PMID:17413050 http://dx.doi. org/10.1378/chest.06-3008

83. Benn CS, Thorsen $P$, Jensen JS, Kjaer BB, Bisgaard $H$, Andersen $\mathrm{M}$ et al. Maternal vaginal microflora during pregnancy and the risk of asthma hospitalization and use of antiasthma medication in early childhood. J Allergy Clin Immunol 2002;110:72-7. PMID:12110824 http://dx.doi. org/10.1067/mai.2002.125833

84. Marri PR, Stern DA, Wright AL, Billheimer D, Martinez FD. Asthma-associated differences in microbial composition of induced sputum. J Allergy Clin Immunol. 2013 Mar;131(2):346-52.e1-3.

85. Huang YJ, Nelson CE, Brodie EL, Desantis TZ, Baek MS, Liu J, et al. Airway microbiota and bronchial hyperresponsiveness in patients with suboptimally controlled asthma. J Allergy Clin Immunol. 2011 Mar;127(2):372-81.e1-3.

86. Hilty M, Burke C, Pedro H, Cardenas P, Bush A, Bossley C et al. Disordered microbial communities in asthmatic airways. PLoS ONE 2010;5:e8578. PMID:20052417 http://dx.doi. org/10.1371/journal.pone.0008578

87. Cardenas PA, Cooper PJ, Cox MJ, Chico M, Arias C, Moffatt MF et al. Upper airways microbiota in antibiotic-naïve wheezing and healthy infants from the tropics of rural
Ecuador. PLoS ONE 2012;7:e46803. PMID:23071640 http:// dx.doi.org/10.1371/journal.pone.0046803

88. Bisgaard H, Hermansen MN, Bønnelykke K, Stokholm J, Baty F, Skytt NL et al. Association of bacteria and viruses with wheezy episodes in young children: prospective birth cohort study. BMJ 2010;341:c4978. PMID:20921080 http:// dx.doi.org/10.1136/bmj.c4978

89. Teo SM, Mok D, Pham K, Kusel M, Serralha M, Troy N et al. The infant nasopharyngeal microbiome impacts severity of lower respiratory infection and risk of asthma development. Cell Host Microbe 2015;17:704-15. PMID:25865368 http:// dx.doi.org/10.1016/j.chom.2015.03.008

90. Bager P, Melbye M, Rostgaard K, Benn CS, Westergaard T. Mode of delivery and risk of allergic rhinitis and asthma. J Allergy Clin Immunol 2003;111:51-6. PMID:12532096 http://dx.doi.org/10.1067/mai.2003.34

91. Roduit C, Scholtens S, de Jongste JC, Wijga AH, Gerritsen J, Postma DS et al. Asthma at 8 years of age in children born by caesarean section. Thorax 2009;64:107-13. PMID:19052046 http://dx.doi.org/10.1136/thx.2008.100875

92. Abrahamsson TR, Jakobsson HE, Andersson AF, Björkstén $B$, Engstrand L, Jenmalm MC. Low gut microbiota diversity in early infancy precedes asthma at school age. Clin Exp Allergy 2014;44:842-50. PMID:24330256 http://dx.doi. org/10.1111/cea.12253

93. Bendiks M, Kopp MV. The relationship between advances in understanding the microbiome and the maturing hygiene hypothesis. Curr Allergy Asthma Rep 2013;13:487-94. PMID:23934550 http://dx.doi.org/10.1007/s11882-0130382-8

94. Hasegawa K, Camargo CA Jr. Airway microbiota and acute respiratory infection in children. Expert Rev Clin Immunol 2015;11:789-92. PMID:25961472 http://dx.doi.org/10.158 6/1744666X.2015.1045417

95. Esposito S, Rigante D, Principi N. Do children's upper respiratory tract infections benefit from probiotics? BMC Infect Dis 2014;14:194. PMID:24720809 http://dx.doi. org/10.1186/1471-2334-14-194

96. Li L, Somerset S. The clinical significance of the gut microbiota in cystic fibrosis and the potential for dietary therapies. Clin Nutr 2014;33:571-80. PMID:24767984 http://dx.doi.org/10.1016/j.clnu.2014.04.004

97. West CE, Jenmalm MC, Prescott SL. The gut microbiota and its role in the development of allergic disease: a wider perspective. Clin Exp Allergy 2015;45:43-53. PMID:24773202 http://dx.doi.org/10.1111/cea.12332

98. Hao $Q$, Dong BR, Wu T. Probiotics for preventing acute upper respiratory tract infections. Cochrane Database Syst Rev 2015;2:CD006895. PMID:25927096 